\title{
Pandemic-related barriers to the success of women in research: a framework for action
}

\begin{abstract}
Women in academia have fallen behind with publications and grant funding during the COVID-19 pandemic and risk dropping out of the research workforce altogether, unless urgent action is taken by institutes and funders.
\end{abstract}

\author{
Pamela B. Davis, Emma A. Meagher, Claire Pomeroy, William L. Lowe Jr, Arthur H. Rubenstein, Joy Y. Wu, \\ Anne B. Curtis and Rebecca D. Jackson
}


he COVID-19 pandemic has struck at the very fabric of academic medicine, causing career uncertainty for many, with a disproportionate impact on underrepresented minorities, LGBT+ scientists, people with disabilities, and those from myriad non-traditional backgrounds. The challenges of the pandemic have been amplified for women, especially due to the additional burden of home caregiver responsibilities. Many women are at risk of dropping out of academic research altogether, unless urgent action is taken.

\section{An increased burden}

The immediate burden of COVID-19 on academic medicine has been the delivery of high-quality clinical care, but there will also be a major long-term negative effect on research ${ }^{1}$, which will most heavily affect women investigators. Surveys of academics showed that the strongest predictors of time lost from research were female sex and the presence of young dependents ${ }^{1}$. Women have dropped out of the US workforce in far greater numbers than men have and are not coming back at the same rate ${ }^{2}$, including in academic medicine ${ }^{3}$.

Considerably more faculty in academic medicine report that they are considering leaving their positions or reducing hours during the pandemic than before, especially female faculty with children. Moreover, women with children were more than three times as likely to decline leadership opportunities as were women without children ${ }^{4}$. Submissions of scholarly papers to the medical literature by women decreased, whereas for men, they increased ${ }^{5,6}$. One department of internal medicine found that the number of grant submissions during the first 12 months of the pandemic increased for male faculty but not for female faculty, and that female faculty were requesting lower dollar amounts in these applications ${ }^{7}$. Other data, from, for example, the US National Institutes of Health (NIH), indicate that overall, the

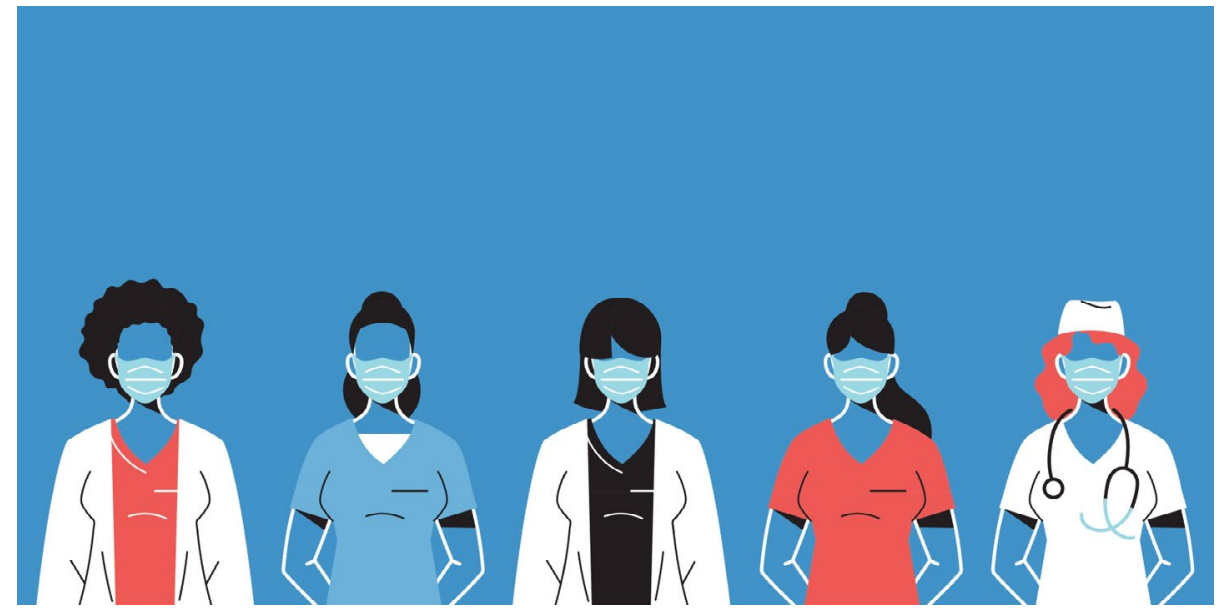

Credit: Diana Johanna Velasquez / Alamy Stock Vector

proportion of women submitting grant applications has not changed much in the pandemic ${ }^{8}$. The NIH data show that women continue to submit entry-level grants in greater numbers, but not career-advancing higher-level applications, such as program project or center grants ('P series') or large collaborative ' $U$ series' grants ${ }^{8}$.

Clinical research has been especially hard hit by the infection-control requirements of the pandemic, and the delay imposed on clinical studies may be hard to overcome. Because grant funding was commonly not suspended (a real institutional asset during the crisis), it now may not extend sufficiently to cover the delay in study completion. Because women are disproportionally overrepresented in clinical research, according to Michael Lauer, Deputy Director for Extramural Research at the NIH, the impact on women will probably be greater.

There is a risk that junior women academics will not be able to meet expectations for tenure or promotion, even if their grants are extended, as they have not been able to publish enough in 2020 and 2021. Indeed, tenure-clock extensions granted during the pandemic, although well intentioned, may inadvertently benefit male faculty, who tend to use them for academic purposes, unlike female faculty, who tend to use them for caregiving responsibilities ${ }^{9}$. There is also a risk that early-career women academics will elect to pursue careers outside of academic medicine or leave the workforce completely, further exacerbating the challenge for women to achieve leadership positions.

\section{Unacceptable baseline status of women}

Women are appropriately represented, or very nearly so, among residents, fellows and assistant professors in academia, but the presence of women diminishes substantially at the level of associate professor, full professor and department chair. Representation of women at these higher ranks has not advanced in the past 35 years $^{10}$. This is despite the efforts of many groups, such as Executive Leadership in Academic Medicine at Drexel University or the mentoring program initiated by 
Table 1 | Recommendations to retain women in the biomedical work force

\begin{tabular}{|c|c|c|}
\hline Stakeholder & $\begin{array}{l}\text { Type of } \\
\text { commitment }\end{array}$ & Recommendations \\
\hline \multirow[t]{11}{*}{ Institution } & \multirow[t]{4}{*}{ Financial } & $\begin{array}{l}\text { Provide short-term, flexible research support of } \$ 50,000-75,000 \\
\text { per year for junior faculty heavily impacted by caregiving } \\
\text { responsibilities }\end{array}$ \\
\hline & & $\begin{array}{l}\text { Provide comparable startup packages to men and women and allow } \\
\text { flexible use of these funds }\end{array}$ \\
\hline & & $\begin{array}{l}\text { Provide central mechanisms for identifying appropriate childcare } \\
\text { and eldercare }\end{array}$ \\
\hline & & $\begin{array}{l}\text { Provide benefits for support of childcare, such as institutional facilities } \\
\text { or tax-exempt accounts to support child care }\end{array}$ \\
\hline & \multirow[t]{2}{*}{ Culture } & $\begin{array}{l}\text { Create the expectation that establishing gender equity is a shared } \\
\text { responsibility and incorporate expectations into bonuses and merit } \\
\text { raises of institutional leaders }\end{array}$ \\
\hline & & $\begin{array}{l}\text { Engage Boards of Trustees of universities and hospitals to support } \\
\text { gender equity }\end{array}$ \\
\hline & \multirow[t]{5}{*}{ Operations } & $\begin{array}{l}\text { Ensure both high-quality mentorship and sponsorship for all } \\
\text { junior faculty }\end{array}$ \\
\hline & & $\begin{array}{l}\text { Offer more senior women national-level leadership preparation } \\
\text { programs, such as ELAM and CWAMS }\end{array}$ \\
\hline & & $\begin{array}{l}\text { Ensure that federal and foundation offerings of supplemental support } \\
\text { are well known to those who could benefit }\end{array}$ \\
\hline & & $\begin{array}{l}\text { Consider retaining a flexible work schedule and continuing use of } \\
\text { technology for communications as life returns toward normalcy }\end{array}$ \\
\hline & & $\begin{array}{l}\text { Pause the promotion timeline during the pandemic and encourage } \\
\text { explanation of reduced productivity periods in the promotion portfolio, } \\
\text { as well as train promotions committee members in how they should } \\
\text { consider such reduction }\end{array}$ \\
\hline \multirow{4}{*}{$\begin{array}{l}\text { Foundations, } \\
\text { professional } \\
\text { societies and } \\
\text { funders }\end{array}$} & \multirow[t]{2}{*}{ Funding } & $\begin{array}{l}\text { Encourage foundations and individual philanthropic donors to develop } \\
\text { supplemental funding initiatives for researchers impacted by } \\
\text { caregiving responsibilities }\end{array}$ \\
\hline & & $\begin{array}{l}\text { Encourage the expansion of federal programs that support childcare } \\
\text { for promising rising investigators }\end{array}$ \\
\hline & \multirow[t]{2}{*}{ Culture } & $\begin{array}{l}\text { Advocate for the societal concept that childcare and eldercare } \\
\text { constitute valuable national infrastructure }\end{array}$ \\
\hline & & $\begin{array}{l}\text { Advocate for professional organizations to celebrate and publicize } \\
\text { effective programs that address gender equity and accommodate } \\
\text { caregiving responsibility, such as the recent statement from the } \\
\text { Clinical Research Forum }\end{array}$ \\
\hline
\end{tabular}

ELAM, Executive Leadership in Academic Medicine; CWAMS, Center for Women in Academic Medicine and Science.

the Center for Women in Academic Medicine and Science, to train women for leadership roles and provide mentorship and sponsorship for women, as well as an insistence by many institutions that searches for upper-level positions include diverse candidate pools.

Women are paid less than men in comparable positions are $\mathrm{e}^{11,12}$, receive lower startup funds for laboratory research, and take longer to be promoted ${ }^{10}$. Women as a group may have fewer of the conventional markers of achievement in academia than do men, including fewer principalinvestigator positions on large NIH grants such as P or U series awards (ref. ${ }^{8}$ and
M. Lauer, personal communication), fewer grant applications and grant renewals ${ }^{13}$, lower funding amounts for initial grants ${ }^{14}$, fewer papers for which they are first or last author ${ }^{15}$, and fewer citations of their papers (including papers authored by women in prestigious journals) ${ }^{16,17}$.

\section{Funds for caregiving responsibilities} Several existing programs offer valuable solutions to prevent the loss of women from academia. The Claflin Distinguished Scholar Awards at Massachusetts General Hospital provide US\$50,000 per year for two years to maintain research productivity during the child-rearing years. The program is competitive, and data indicate that those who were selected had a higher retention rate at their institution $(90 \%$, versus $60 \%$ for those who applied but were not selected for the program). Of note, the program invested $\$ 2.1$ million over an eight-year period and garnered a very substantial return on investment, with $\$ 51$ million in direct costs in grants being awarded to the recipients ${ }^{18}$.

The Doris Duke Charitable Foundation developed the Fund to Retain Clinical Scientists, through which support is awarded at the institutional level and is targeted to early-career faculty conducting clinical research who need supplemental resources because of caregiving responsibilities ${ }^{19,20}$. Providing laboratory support allows women to devote their time to other academic activities. Institutional matching funds, although not required as a condition of grant funding, were often provided to pay for child or elder care. The Doris Duke Charitable Foundation reissued this grant offering in 2021 and has formed an alliance with other foundations, including the American Heart Association, the Burroughs Wellcome Fund, the Rita Allen Foundation and the Walder Foundation. The NIH now offers $\$ 2,500$ to support childcare to recipients of National Research Service Awards, but this has not been extendedto other awards. In late 2019, the NIH launched supplements to "promote the continuity of the research project... during a period [of] critical life events" by purchasing extra technical assistance for faculty ' $\mathrm{K}$ award' recipients and holders of early stage R01 grants $^{21,22}$.

\section{A framework for retaining women in academic research}

We provide here a 'menu' of possible interventions to reduce the attrition of women from academia (Table 1). Both financial investment and commitment to cultural and operational changes are important to pursue at the institutional level, and there is room for creativity and flexibility beyond these recommendations ${ }^{23,24}$. Among stakeholders such as foundations, government funders, and professional organizations, there are already important examples of programs designed to mitigate the impact of COVID-19 on research by women. Expansion of such programs and investment in other innovative measures will be needed to prevent considerable loss of talent at early-career levels. Finally, and perhaps most importantly, substantial national and global efforts to change societal norms that position women as the default responsible caregivers are critical to allow women to succeed in the workforce, including in academic research careers. 
Pamela B. Davis (iD) ${ }^{凶}$, Emma A. Meagher ${ }^{2}$ Claire Pomeroy ${ }^{3}$, William L. Lowe Jr(B) ${ }^{4}$, Arthur H. Rubenstein ${ }^{2}$, Joy Y. Wu (D) ${ }^{5}$, Anne B. Curtis ${ }^{6}$ and Rebecca D. Jackson ${ }^{7}$ ${ }^{1}$ Center for Community Health Integration, Case Western Reserve University School of Medicine, Cleveland, OH, USA. ${ }^{2}$ Department of Medicine, Raymond and Ruth Perelman School of Medicine, University of Pennsylvania, Philadelphia, PA, USA. ${ }^{3}$ Albert and Mary Lasker Foundation, New York, NY, USA. ${ }^{4}$ Department of Medicine, Northwestern University Feinberg School of Medicine, Chicago, IL, USA. ${ }^{5}$ Department of Medicine, Stanford University School of Medicine, Stanford, CA, USA. ${ }^{6}$ Department of Medicine, Jacobs School of Medicine and Biomedical Sciences, University at Buffalo, Buffalo, NY, USA. ${ }^{7}$ Department of Medicine, The Ohio State University, Columbus, OH, USA.

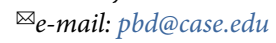

Published online: 17 February 2022 https://doi.org/10.1038/s41591-022-01692-8

\section{References}

1. Myers, K. R. et al. Nat. Hum. Behav. 4, 880-883 (2020).

2. Ewing-Nelson, C. National Women's Law Center https://nwlc.org/ wp-content/uploads/2021/01/December-Jobs-Day.pdf (January 2021)
3. Mandavilli, A. The New York Times https://www.nytimes.com/ 2021/04/13/health/women-stem-pandemic.html (accessed 6 December 2021).

4. Matulevicius, S. A. et al. JAMA Netw. Open 4, e2113539 (2021).

5. Wehner, M. R., Li, Y. \& Nead, K. T. I. JAMA Netw. Open 3 , e2020335 (2020).

6. Pinho-Gomes, A. C. et al. BMJ Glob. Health 5, e002922 (2020).

7. Wu, J. The Clayman Institute for Gender Research https://gender. stanford.edu/news-publications/gender-news/pandemicmagnifies-gender-inequities-provides-opportunities-long-range (19 July 2021).

8. Lauer, M. NIH Extramural Nexus https://nexus.od.nih.gov/all/ 2021/06/01/an-updated-look-at-applications-submittedduring-the-pandemic/ (1 June 2021).

9. Antecol, H. et al. Am. Econ. Rev. 108, 2420-2441 (2018). 10. Richter, K. P. et al. N. Engl. J. Med. 383, 2148-2157 (2020).

11. U.S. Department of Labor Women's Bureau. https://www.dol.gov/ agencies/wb/news/newsletter/march2021 (March 2021).

12. Lo Sasso, A. T. et al. Health Aff. 39, 256-263 (2020).

13. Hechtman, L. A. et al. Proc. Natl Acad. Sci. USA 115, 7943-7948 (2018).

14. Oliveira, D. F. M. et al. J. Am. Med. Assoc. 321, 898-900 (2019).

15. Kibbe, M. R. JAMA Surg. 195, 803-804 (2020).

16. Burstin, H. R. \& Arora, V. M. JAMA Netw. Open 4, e 2114787 (2021).

17. Chaterjee, P. \& Werner, R. M. JAMA Netw. Open 4, e2114509 (2021).

18. Jagsi, R. et al. Arch. Intern. Med. 167, 343-345 (2007).

19. Jones, R. D. et al. Acad. Med. 94, 1746-1756 (2019).

20. Jagsi, R. et al. Ann. Intern. Med. 169, 128-130 (2018).

21. US National Institutes of Health. https://grants.nih.gov/ grants/guide/notice-files/NOT-OD-20-055.html (accessed 6 December 21).

22. US National Institutes of Health. https:/grants.nih.gov/grants/ guide/notice-files/NOT-OD-20-054.html (accessed 6 December 21)
23. Fuentes-Afflick, E. \& Higginbotham, E. N. Engl. J. Med. 384, 2265-2267 (2021).

24. National Academies of Sciences, Engineering, and Medicine. The Impact of COVID-19 on the Careers of Women in Academic Sciences, Engineering, and Medicine (eds. Higginbotham, E. \& Dahlberg, M.L.) (The National Academies Press, 2021); https://doi.org/10.17226/26061

25. Clinical Research Forum. https://www.clinicalresearchforum.org/ page/impactofthepandemic (2022).

\section{Acknowledgements}

We gratefully acknowledge the Clinical Research Forum Board of Directors for constituting the Academic

Advancement Committee, whose members became the authors of this paper, for helpful discussion of the data and the recommendations, and for their support of women in academic medicine. Other than authors of this paper, the members of the Clinical Research Forum Board are

H. Selker, H. Pardes, R. Califf, B. Coller, M. Fava, H. Greenberg, R. Kaushal, A. Reece, A. Shenkhar and D. Ford.

\section{Author contributions}

P.B.D. wrote the manuscript and integrated edits from other authors. Important discussion and extensive editing was provided by all authors.

\section{Competing interests}

P.B.D., E.A.M., W.L.L., A.H.R., A.B.C. and R.D.J. serve on the Board of Directors of the Clinical Research Forum. R.D.J. has received a grant from the Doris Duke Charitable Foundation. P.B.D., C.P. and A.H.R. are members of the Board of Directors of the Center for Women in Academic Medicine and Science.

\section{The hospital-at-home presents novel liabilities for physicians, hospitals, caregivers, and patients}

Healthcare is increasingly provided in a patient's home, with potential cost savings and clinical improvements. But the hospital-at-home also raises unique liability issues not only for physicians and hospitals but also for caregivers and patients.

\section{David A. Simon, I. Glenn Cohen, Celynne Balatbat and Anaeze C. Offodile II}

T he COVID-19 pandemic has spurred hospitals to increasingly implement remote care models that replace in-patient care - from checkups to diagnosis to treatment - with services delivered in the patient's home, known as the 'hospital-at-home' ( $\mathrm{HaH})(\mathrm{Box} 1)$. Such patients typically move through the $\mathrm{HaH}$ in the same way that a patient moves through a traditional hospital: admission, monitoring, intervention, and discharge. But there are differences. Care occurs in the patient's home, rather than in the hospital, which requires that the $\mathrm{HaH}$ providers use physicians, nurses, technicians, and caregivers in different ways from their use in the traditional hospital setting, such as telehealth or house visits. The $\mathrm{HaH}$ has potentially substantial economic and health benefits and has been associated with reduced risk of infections, increased mobility for patients, cost savings, and improved clinical outcomes ${ }^{1,2}$. Despite these potential benefits, the $\mathrm{HaH}$ poses several pressing legal and ethical challenges, including legal liability, that must be resolved for its safe, ethical, and effective implementation.

A clinical vignette (Fig. 1) can be used to demonstrate and map the unique and complex liability issues likely to arise in the HaH setting, including liability for physicians, hospitals, and third-party service providers ${ }^{3}$. Some potential liability, such as liability for admission decisions or delayed response times, exists in the hospital setting but applies to the $\mathrm{HaH}$ in a unique way. Other potential liability, such as liability arising from dangerous conditions at the patient's home, is unique to the $\mathrm{HaH}$ setting (Table 1).

\section{Physician liability}

Under US tort law, when caring for patients, physicians must provide a certain standard of care: they must, depending on the state in which they practice, act either according to the "generally recognized and accepted practices in their profession" or as a "reasonable physician under similar circumstances" would act ${ }^{4-6}$. Although 